\title{
Influence of Poly(vinyl chloride) on Natural Rubber/Chlorosulfonated Polyethylene Blends
}

\author{
Manisara Phiriyawirut, Sawanya Luamlam \\ Department of Tool and Materials Engineering, King Mongkut's University of Technology Thonburi, Bangkok, Thailand \\ Email: manisara.pee@kmutt.ac.th
}

Received July 5, 2013; revised August 5, 2013; accepted August 12, 2013

Copyright (C) 2013 Manisara Phiriyawirut, Sawanya Luamlam. This is an open access article distributed under the Creative Commons Attribution License, which permits unrestricted use, distribution, and reproduction in any medium, provided the original work is properly cited.

\begin{abstract}
Blend of natural rubber (NR) and chlorosulfonated polyethylene (CSM) was so interesting due to binding of the good oil resistance of CSM, the good mechanical properties and low cost of NR. However, due to the different polarities of two rubbers, phase separation and inferior properties of NR/CSM blend were obtained. The practical way to improve its properties is the addition of the third component to bind both phases of the blend. Effects of poly(vinyl chloride), PVC as compatibilizer on cure characteristics, morphology, mechanical properties and automotive fuel resistance of NR/ CSM blend were investigated. In this contribution, NR/CSM blend with blend ratio of 50/50 was prepared using a tworoll mill, and then vulcanized in a compression mold at $160^{\circ} \mathrm{C}$. The PVC content was varied from 1 to 7 phr. It was found that the usage of $7 \mathrm{phr}$ PVC led to improve interaction between NR and CSM phases. Therefore, increase in cure characteristics, mechanical strength and automotive fuel resistance of the blend was observed.
\end{abstract}

Keywords: Natural Rubber; CSM Rubber; Blend; Compatibilizer; Fuel Resistance; PVC

\section{Introduction}

Elastomer blending is a reforming technique to develop new material, which is able to control desired properties to meet the requirement in making auto parts. It is frequently used in the rubber industry to obtain the best compromise in compound physical properties, processability and cost [1]. However, blending of two elastomers usually leads to immiscibility, and the desired properties are not achieved without a third component, i.e., a compatibilizer, which is able to mediate an attractive interaction between the phases [2]. Natural rubber (NR) is deteriorated by ozone and thermal attack due to a highly unsaturated backbone, and it also shows low oil and chemical resistance due to non-polarity. Blending NR with other high oil resistance rubber has been reported in many articles such as blending with ethylene-propylenediene rubber [3] dichlorocarbene modified styrene butadiene rubber [4] or chloroprene rubber [5]. Chlorosulfonated polyethylene (CSM) is an important synthetic rubber. Vulcanized CSM is highly resistant to the deteriorating effects of ozone, oxygen, weather, heat, oil, and chemicals. Owing to the presence of the polarity of the chlorine group in CSM, NR/CSM blends should be resistant to ozone, oil, heat, flame, and nonpolar chemicals. Based on chemical structure, the NR/CSM blend becomes incompatible due to the difference in polarity. The resulting materials exhibit poor mechanical properties due to the poor adhesion between the phases.

Several trials were carried out to minimize the phase separation and increase interfacial adhesion; these included the addition of physical or chemical compatibilizers [6-8] (the addition of a third homopolymer or graft or block copolymer) that binded with the two phases and introduced the covalent bonds between the homopolymer phases. The compatibilizer also reduces the interfacial tension that is responsible for phase separation. Poly(vinyl chloride) (PVC) contains ethylene group as main chain and vinyl group of chlorine which are reacted to NR and CSM molecules, respectively. It has similarity in the molecular structure of PVC with the other two kinds of rubber phases (NR and CSM) as shown in Figure 1. Thus, PVC is a potentially good candidate for using as a compatibilizer in NR/CSM blend.

Curing characteristics, morphology, and mechanical properties of rubber blend were studied. Automotive fuel resistances of 50/50 NR/CSM blends with and without PVC were also investigated. 


\section{Experimental}

\subsection{Materials}

The natural rubber used in this study was STR5L, produced in Thailand. Chlorosulfonated polyethylene (Hypalon $^{\circledR} 40$ ) was supplied by DuPont. PVC, Mw $=67 \mathrm{KDa}$, was supplied by TPC, Thailand. All chemicals for rubber compounding were commercial grade and used as received. The selected automotive fuels in this experiment were gasoline, gasohol, diesel and B5-biodiesel which supplied from petroleum station of PTT Public Co., Ltd., Thailand. The gasohol is $10 \%$ of ethanol blended with conventional gasoline and B5-biodiesel is 5\% of biodiesel blended with conventional diesel.

\subsection{Mixing and Vulcanization Procedure}

The compound ingredients as shown in Table $\mathbf{1}$ were mixed on two-roll mill at room temperature. To Vulcanize the blends, the mixes were compression molded using a hydraulic hot press at $160^{\circ} \mathrm{C}$ under pressure $15 \mathrm{MPa}$ according to the respective cure times determined by<smiles>CC=C(C)CC</smiles>

Naturl rubber, NR

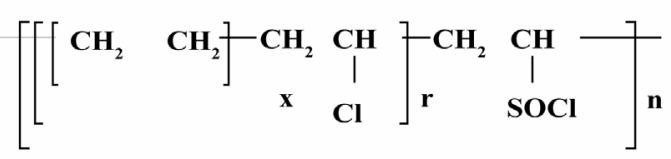

Chloro sulfonated polyethylene, CSM

Figure 1. Chemical structure of investigated polymers.

Table 1. Formulations of NR/CSM blends with and without PVC.

\begin{tabular}{cccccc}
\hline \multirow{2}{*}{ Ingredients } & \multicolumn{5}{c}{${\text { Content }(\mathrm{phr})^{\mathrm{a}}}^{\mathrm{c}}$} \\
\cline { 2 - 6 } & 1 & 2 & 3 & 4 & 5 \\
\hline NR (STR 5L) & 50 & 50 & 50 & 50 & 50 \\
CSM & 50 & 50 & 50 & 50 & 50 \\
PVC & 0 & 1 & 3 & 5 & 7 \\
Sulfur & 2 & 2 & 2 & 2 & 2 \\
6PPD & 4 & 4 & 4 & 4 & 4 \\
MgO & 5 & 5 & 5 & 5 & 5 \\
Stearic acid & 2 & 2 & 2 & 2 & 2 \\
TMTD $^{\mathrm{c}}$ & 1 & 1 & 1 & 1 & 1 \\
\hline
\end{tabular}

${ }^{\mathrm{a}}$ phr, parts per hundred; ${ }^{\mathrm{b}} 6 \mathrm{PPD}, N$-(1,3-dimethylbutyl)- $N$ '-phenyl-p-phenylenediamine; ${ }^{\mathrm{C}} \mathrm{TMTD}$, Tetramethyl thiuram disulfide. oscillating disk rheometer machine (ODR GT-707052). The ODR gives digitals outputs of curing characteristics such as scorch time, cure times and torque value.

\subsection{Testing}

Morphological test: Morphological study was carried out using the Philips, XL30CP scanning electron microscope with $20 \mathrm{kV}$ accelerating voltage with complementary surface preparation techniques via $\mathrm{OsO}_{4}$ staining to improve the phase contrast. Each sample was coated with a thin layer of gold prior to observation under SEM.

Mechanical tests: Tensile and tear specimens were punched out from the molded slab using an ASTM standard die. The mechanical tests were carried out per the ASTM D412 and ASTM D1004 for tensile test and tear test, respectively. The Instron 2532 tensile tester and LLOYD tear resistance tester were both examining at a crosshead speed of $500 \mathrm{~mm} / \mathrm{min}$ with load cell of $500 \mathrm{~N}$.

Automotive fuel resistance tests: The automotive fuel resistance tests were carried out per the ASTM D471. Square test specimens of $2 \times 2 \times 2 \mathrm{~cm}^{3}$ were weighed accurately before immersing into automotive fuel at 25 and $70^{\circ} \mathrm{C}$. After a specific time of swelling, the specimen was removed from the fuel and weighed again after re-moving surface fluids by blotting with filter paper. The percentage of swelling was calculated according to the following equation

$$
\% \text { swelling }=\frac{W_{2}-W_{1}}{W_{1}} \times 100
$$

where $\mathrm{W}_{1}$ and $\mathrm{W}_{2}$ represent the weight of the specimens after and prior to immersion into automotive fuel.

\section{Results and Discussion}

\subsection{Cure Characteristic}

The effect of PVC content on cure characteristic of NR/ $\mathrm{CSM}$ blend at $160^{\circ} \mathrm{C}$ was investigated by ODR. The cure characteristics of NR/CSM blends i.e., scorch time, cure time and different in torque values of NR/CSM rubber blends specimen before and after curing (MH-ML) were shown in Figure 2.

The scorch times of blends were found no significantly changed by increasing PVC content. It has no effect on scorch time and cure time by increasing of PVC in the NR/CSM blend. PVC content at 1 to 5 phr in NR/CSM blend had no effect on the different torque values $(\mathrm{MH}-$ ML), but it was gradually increased by increasing PVC content from 5 to 7 phr. NR/CSM blending without PVC has low MH-ML value due to less interaction between NR and CSM molecules, however, addition 1 to 5 phr of PVC do not increase the MH-ML value because of insufficient of PVC content in the blend that can enhance binding between two phases. The higher PVC content 

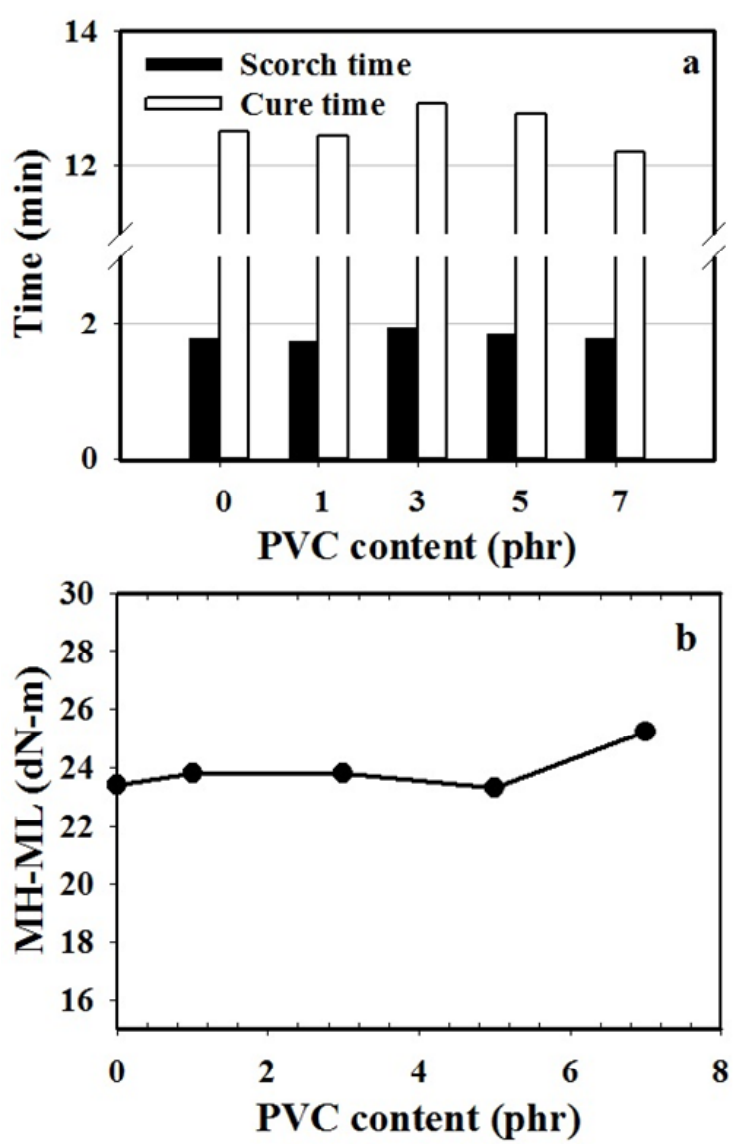

Figure 2. Cure characteristics of NR/CSM blends with different PVC content (a) cure time and scorch time and (b) different torque values (MH-ML).

between 5 to $7 \mathrm{phr}$, the higher torque of ODR was achieved. The increasing of ODR torque is the effect on increasing of polarity which results in more interaction between two phases of rubber blend.

Work related to the compatible PVC/chlorinated polyurethane blend was studied by Pielichowsk [9]. The compatibility of two phases were explained in the terms of specific interactions between $\mathrm{C}=\mathrm{O}$ and $\mathrm{Cl}$ groups. It is well known that chlorinated polymers are miscible with many polyesters and it has been shown that the miscibility of these blends can be enhanced by hydrogen bonding between the $\mathrm{C}=\mathrm{O}$ groups of the polyester and the alpha-hydrogen of chlorinated polymer or a dipoledipole $-\mathrm{C}=\mathrm{O} \cdot \cdots \cdot \mathrm{Cl}-\mathrm{C}-$ interaction. On this basic and taking into account previous results for compatible blends of PVC and chlorinated polyurethane, it can be deduced that not only hydrogen bonding between alphahydrogen atom of PVC and $-\mathrm{S}=\mathrm{O}$ group of CSM but also dipole-dipole interaction between $-\mathrm{S}=\mathrm{O}$ of $\mathrm{CSM}$ and $\mathrm{Cl}$ atom of $\mathrm{PVC}$ were formed. Moreover, aliphatic main chain of PVC can blend and entangle to non-polar NR chains.

In addition, the higher MH-ML value is represented crosslink density in rubber phases. Addition 7 phr of
PVC into NR/CSM blend gives the highest crosslink in the rubber blend.

\subsection{Morphological Properties}

The SEM micrographs of the fracture surfaces shows higher surface roughness of the NR/CSM blend with PVC (Figures 3(b)-(d)) when compared with the blend without PVC (Figure 3(a)). The fracture surface of the NR/CSM blend without PVC showed the immiscible blend morphology. The improved interfacial adhesion in case of the compatiblized blend rendered the surrounding matrix to be tightly held by the elastomer domains during fracture, which caused the texture of the fracture surface to loose its flatness owing to three-dimensional distribution of dispersed domains. However, for different PVC content, the morphology was seem to not significantly different.

\subsection{Mechanical Properties}

The mechanical properties, in terms of tensile strength, modulus at $100 \%$ and $300 \%$ elongation, elongation at break, tear strength and hardness were determined for NR, CSM and a series of NR/CSM rubber blends with and without PVC component and the results were represented t in Figures 4 and 5, respectively.

For pure NR cured specimen, the tear strength, tensile strength, and the percentage of elongation at break were
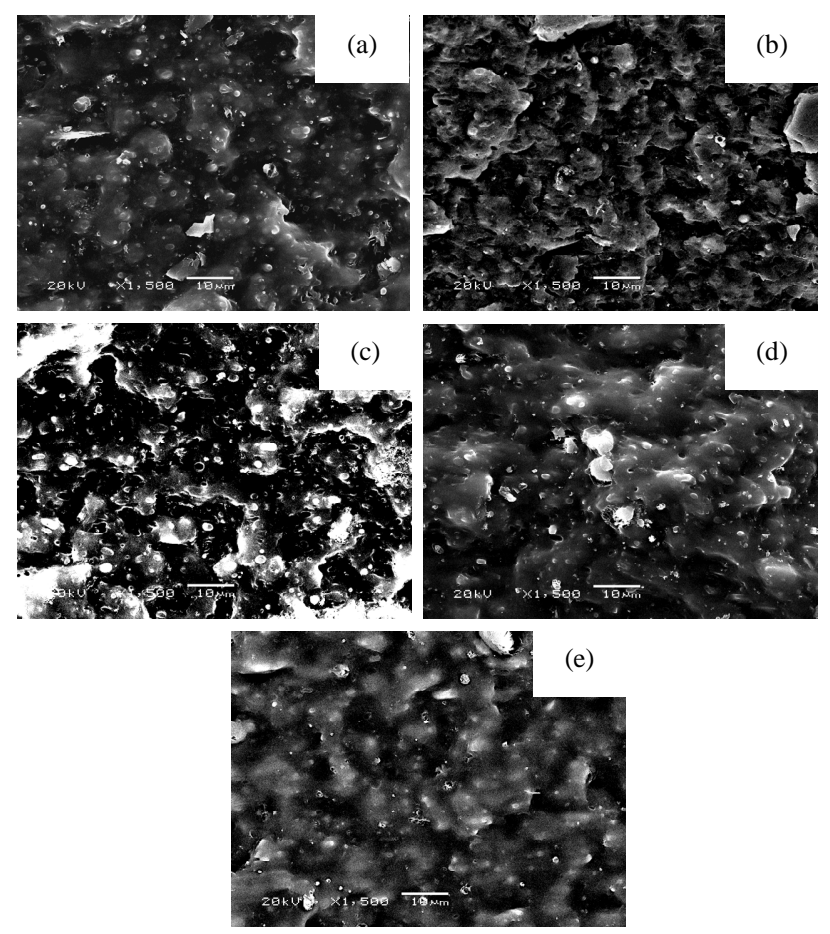

Figure 3. Scanning electron micrograph of fracture surface NR/CSM blend with different PVC content (a) 0 phr (b) 1 phr (c) 3 phr (d) 5 phr and (e) 7 phr. 

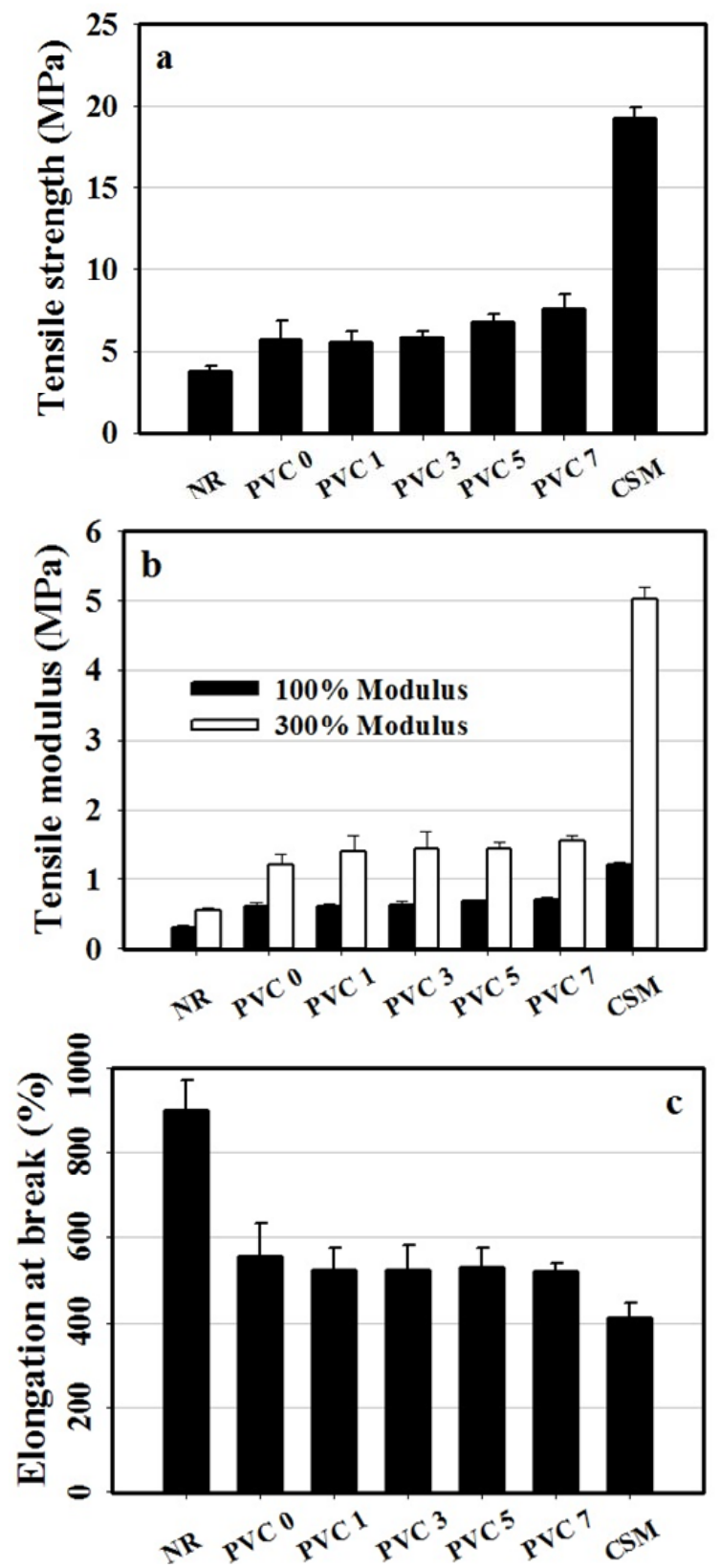

Figure 4. Tensile properties of NR, CSM and NR/CSM blends with different PVC contents at $25^{\circ} \mathrm{C}$ (a) tensile strength, (b) tensile modulus and (c) elongation at break.

found to be ca. $12.41 \mathrm{~N} / \mathrm{mm}$, $3.79 \mathrm{MPa}$, and $898.1 \%$, respectively. On the other hand, CSM exhibited a much stronger characteristic, with its tear strength, tensile strength, and the percentage of elongation at break being ca. $30.31 \mathrm{~N} / \mathrm{mm}, 19.27 \mathrm{MPa}$ and $412 \%$, respectively. For 50/50 NR/FKM blends without PVC component, it was found that the rubber blends were quite stronger than NR. However, the mechanical properties of the blend were not good enough because of lacking of interaction between NR and CSM molecule due to different in polarity of NR comparing to the CSM rubber.
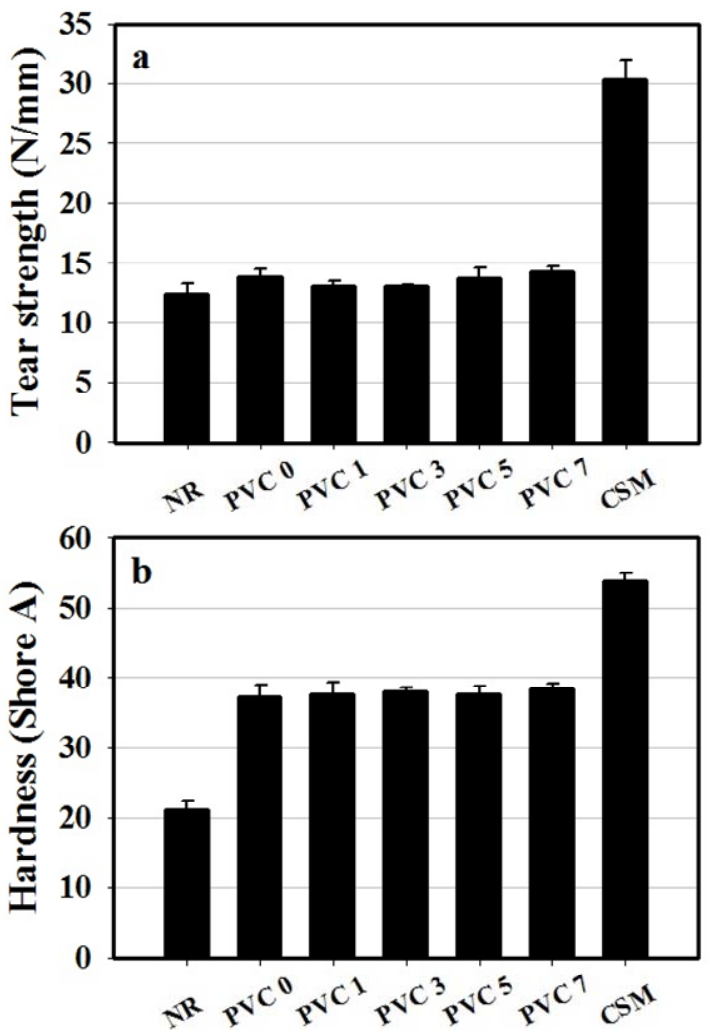

Figure 5. (a) Tear strength and (b) hardness of NR, CSM and NR/CSM blends with different PVC contents at $25^{\circ} \mathrm{C}$.

The mechanical properties of NR/CSM blends were found to be increased by addition of PVC, but it has no effect in increasing PVC content in the mechanical properties except tensile strength which is increased by increasing PVC content. It was shown that the mechanical properties of the blend exhibited some extent of improvement with the addition of PVC. This was due to the achievement of weak dipole-dipole interaction between PVC and CSM molecule. However, the content of PVC which adding into the blend showed no effect on tear strength and tensile modulus. This was due to insufficient PVC molecules to bond between NR and CSM molecule.

Furthermore, the higher strength and lower elasticity of the blend is due to high degree of crosslinking which confirmed by ODR results. The results are clearly in good agreement with the cure characteristic results.

The hardness of NR pure NR cured specimen was found to be ca. 21 Shore A while CSM cure specimen was 53.77 Shore A. For the rubber blend without PVC was 37.17 Shore A which intermediated between the pure components. However, the hardness of NR/CSM blend was not effect by PVC addition and content of PVC.

\subsection{Automotive Fuel Resistance}

CSM is very well known for its excellent swelling resis- 
tance characteristics in hydrocarbon fluids. In the other hand, NR is non-polar rubber with low oil and solvent resistant behavior. NR/CSM blend was found to lower resistance to automotive fuel due to the lack of interaction between NR and CSM phase leading to the weakest point at interphase and resulted to high penetrated of fuel into rubber blend. In rubber blends, the changes in oil resistance as functions of compatibilizer had previously been reported [10]. The compatibilizer help to reduce phase size of rubber blend and improve in morphological stability by lowering the interfacial tension between the phases, and leading in higher oil resistance.

The effect of PVC content of NR/CSM blend on automotive fuel was investigated by determined the percenttages of swelling. The swelling temperature with 25 and $70^{\circ} \mathrm{C}$ was also investigated. The percentages of swelling of a series of NR/CSM blends with different PVC content was shown in Figure $\mathbf{6}$ as a function of immersion time in selected automotive fuels.

After interval of immersion time, it is interesting to note that the percentage of swelling of NR/CSM blend
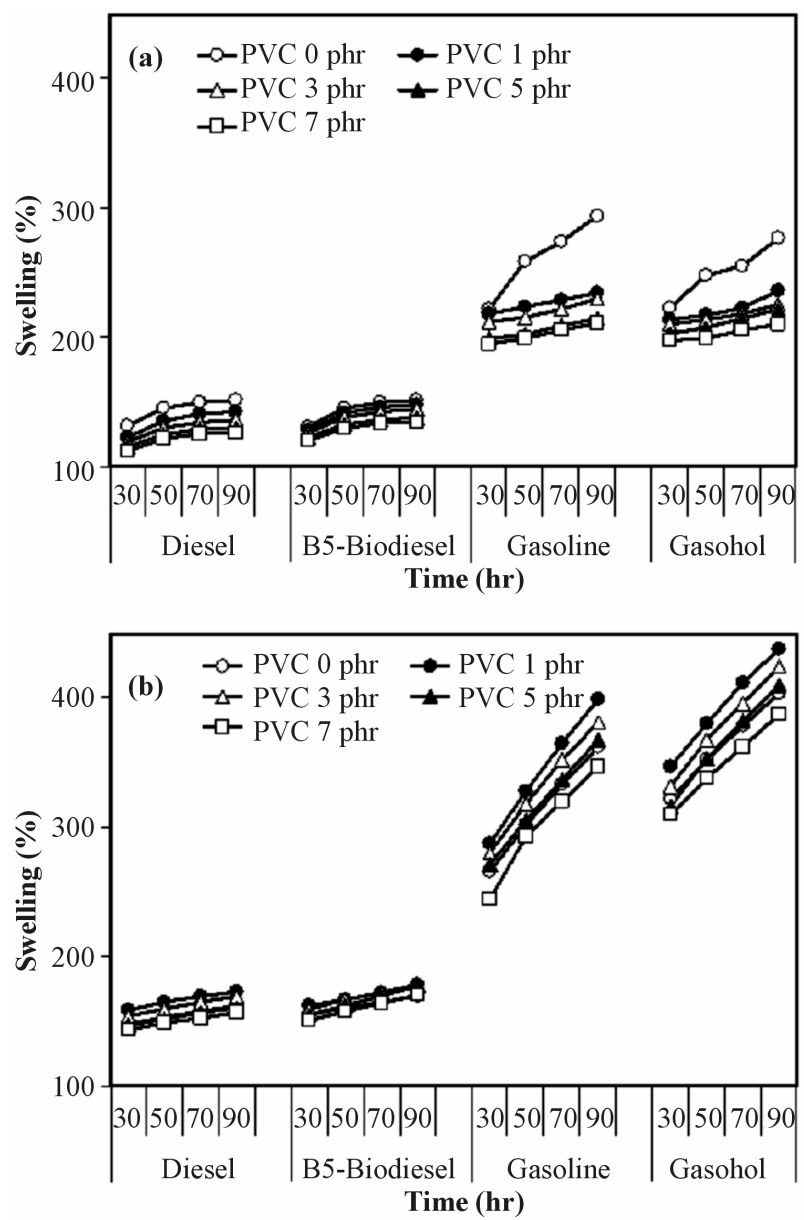

Figure 6. Percentage of swelling in selected automotive fuels of NR/CSM blend with different PVC contents for various immersion time at (a) $25^{\circ} \mathrm{C}$ and (b) $70^{\circ} \mathrm{C}$. without PVC was greater than that of NR/CSM blend with PVC. For all selected automotive fuels, increasing PVC content, the percentage of swelling of NR/CSM blends was found to decrease, when PVC content is increased from 1 to $7 \mathrm{phr}$. The NR/CSM blend with high PVC content showed lower degree of swelling than those of the lower PVC content. Because of the improvement of interaction between NR and CSM by PVC molecule at enough PVC content. In addition, PVC is a polar molecule, so increasing PVC in rubber blend was result in increasing polarity of the rubber blend. Consequently, PVC resisted the penetration of fuel molecules in to the rubber phases, thereby reducing the swelling.

In term of type effect of automotive fuels, it was found that the percentage of swelling of NR/CSM blend with $\mathrm{PVC}$ in gasoline-based fuel was much greater than that in diesel-based fuel. The gasoline-based fuels were smaller molecular size than those of diesel-based fuel. The molecular size of fuel will reflect to the viscosity and penetration ability into rubber phase. Thus gasoline-based fuels were penetrated in ENR added rubber sample easily than diesel-based fuels. However, for comparing in percentage of swelling of these rubber blends in gasolinebased fuel, gasoline and gasohol, it was found slight different. The results were also achieved in between diesel-based fuel, diesel and B5-biodiesel.

For a given blend composition, the percentages of swelling increased by increasing immersion time. The rate of swelling increased exponentially with time. Furthermore, the percentages of swelling of the blends were found to increase at high temperature due to the high temperature, rubber molecule had trend to easier motive. Then molecules of fuel were more penetrated into the rubber phase, result in increasing percentage of swelling.

\section{Conclusion}

NR/CSM blend with blend ratio of 50/50 was prepared by using a two-roll mill and vulcanizes in a compression mold at $160^{\circ} \mathrm{C}$. Effects of PVC content on curing characteristics, morphology, mechanical properties, and automotive fuel resistance of the rubber blends were investigated. It has been found that PVC could function as a compatibilizer in the blend system studied. The optimal concentration of PVC is 7 phr. Beyond this concentration, good mechanical properties and automotive fuel resistance were achieved.

\section{Acknowledgements}

The financial support from Thailand Research Fund (TRF) based on "Small Projects on Rubber Project, SPR 50” and Department of Tool and Materials Engineering, King Mongkut's University of Technology Thonburi are gratefully acknowledged. 


\section{REFERENCES}

[1] D. J. Zanzig, F. L. Magnus, W. L. Hsu, A. F. Halasa and M. E. Testa, "IBR Block Copolymers as Compatibilizers in NR/BR Blends," Rubber Chemistry and Technology, Vol. 66, No. 4, 1993, pp. 538-549.

http://dx.doi.org/10.5254/1.3538326

[2] R. Holsti-Miettinen, J. Seppälä and O. T. Ikkala, "Effects of Compatibilizers on the Properties of Polyamide/Polypropylene Blends," Polymer Engineering \& Science, Vol. 32, No. 13, 1992, pp. 868-877. http://dx.doi.org/10.1002/pen.760321306

[3] S. H. EL-Sabbagh, "Compatibility Study of Natural Rubber and Ethylene-Propylene-Diene Rubber Blends,” Journal of Applied Polymer Science, Vol. 90, No. 1, 2003, pp. 1-11. http://dx.doi.org/10.1002/app.12345

[4] M. T. Ramesan, "Thermogravimetric Analysis, Flammability and Oil Resistance Properties in Natural Rubber and Dichlorocarbene Modified Styrene Butadiene Rubber Blends," Reactive and Functional Polymers, Vol. 59, No. 3, 2004, pp. 267-274. http://dx.doi.org/10.1016/j.reactfunctpolym.2004.02.005

[5] K. Saguan, T. Suteewong, P. Saendee, U. Buranabunya and P. Tangboriboonrat, "Composite Natural Rubber Based Latex Particles: A Novel Approach,” Polymer, Vol. 46, No. 4, 2005, pp. 1373-1378. http://dx.doi.org/10.1016/j.polymer.2004.11.074

[6] A. Y. Coran and R. Patel, "Rubber-Thermoplastic Com- positions 1. EPDM-Polypropylene Thermoplastic Vulcanizates,” Rubber Chemistry and Technology, Vol. 53, No. 1, 1980, pp. 141-150. http://dx.doi.org/10.5254/1.3535023

[7] A. P. Plochocki, S. S. Dagli and R. D. Andrews, "Interface in Binary Mixtures of Polymers Containing a Corresponding Block Copolymer. Effects of Industrial Mixing Processes and of Coalescence,” Polymer Engineering and Science, Vol. 30, No. 12, 1990, pp. 741-752. http://dx.doi.org/10.1002/pen.760301207

[8] H. Ismail and H. M Hairunezam, "The Effect of a Compatibilizer on Curing Characteristics, Mechanical Properties and Oil Resistance of Styrene Butadiene Rubber/Epoxidized Natural Rubber Blends," European Polymer Journal, Vol. 37, No. 1, 2001, pp. 39-44. http://dx.doi.org/10.1016/S0014-3057(00)00099-9

[9] K. Pielichowski and I. Hamertor, "Compatible Poly(vinyl chloride)/Chlorinated Polyurethane Blend: Thermal Characteristics,” European Polymer Journal, Vol. 36, No. 1, 2004, pp. 171-181. http://dx.doi.org/10.1016/S0014-3057(99)00054-3

[10] C. Sirisinha, P. Saeouic and J. Guaysomboona, “Oil and Thermal Aging Resistance in Compatibilized and Thermally Stabilized Chlorinated Polyethylene/Natural Rubber Blends,” Polymer, Vol. 45, No. 14, 2004, pp. 49094915. http://dx.doi.org/10.1016/j.polymer.2004.05.015 